\title{
Association of Time since Migration from Rural to Urban Slums and Maternal and Child Outcomes: Dhaka (North and South) and Gazipur City Corporations
}

\author{
Abdur Razzaque • Kimberly Clair (D) B Bian Chin • Mohammad Zahirul Islam • \\ Mohammad Nahid Mia • Razib Chowdhury • AHM Golam Mustafa • Randall Kuhn
}

Published online: 19 November 2019

(C) The New York Academy of Medicine 2019

\begin{abstract}
This study analyzes data from a new Urban Health and Demographic Surveillance (UHDSS) in five slums in Dhaka (North and South) and Gazipur City Corporations to examine the relationship between migration status and maternal and child health service utilization. Migration status was determined by duration in urban slums $(<=9.99$ years, $10-19.99$ years, $20+$ years, and urban-born). Compared to those born in the city, migrants were characterized by significant disadvantages in every maternal, neonatal, and child health $(\mathrm{MNCH})$ indicator under study, including antenatal care, facility-based delivery, doctor-assisted delivery, child immunization, caesarean-section delivery, and use of modern contraceptives. We found that the level of service coverage among migrants gradually
\end{abstract}

Electronic supplementary material The online version of this article (https://doi.org/10.1007/s11524-019-00395-9) contains supplementary material, which is available to authorized users.

A. Razzaque $\cdot$ M. N. Mia · R. Chowdhury · A. G. Mustafa International Centre for Diarrheal Disease Research, Bangladesh, Health System and Population Studies Division, Dhaka, Bangladesh

K. Clair $(\bowtie) \cdot$ R. Kuhn

Department of Community Health Sciences, University of California, Los Angeles, Fielding School of Public Health, Los Angeles, CA, USA

e-mail: k.clair@ucla.edu

B. Chin

Asian Development Bank, Manila, Philippines

M. Z. Islam

Embassy of Sweden, Dhaka, Bangladesh converged - but did not fully converge - to that of the urban-born with increasing duration in the city. We observed a strong positive association between wealth and total $\mathrm{MNCH}$ coverage, with a more modest association with higher levels of schooling attainment. Women who were engaged in market employment were less likely to receive adequate coverage, suggesting a tradeoff between livelihood attainment and motherand-child health. After controlling for these socioeconomic and neighborhood variations in coverage, the duration gradient was diminished but still significant. In line with existing studies of healthcare access, this study highlights the persistent and widespread burden of unequal access to maternal and child health care facing migrants to slum areas, even relative to the overall disadvantages experienced in informal settlements.

Keywords Maternal and child health · Rural-urban migration $\cdot$ Dhaka $\cdot$ Bangladesh

\section{Introduction}

The urban population of Bangladesh is growing at a rate of $3.8 \%$ each year, primarily as a result of rural to urban migration $[1,2]$. In South Asia, rural-urban migrants tend to be young and driven by opportunities for educational and economic advancement [3-5]. Exposure to environmental vulnerabilities and loss of rural livelihoods have also motivated individual and family migration to urban areas $[6,7]$. While the "healthy migrant hypothesis" suggests that migrants tend to be healthier 
than the populations within destination cities [8, 9], processes of assimilation to urban life and migrants' post-migration health status also contribute to differences in migrant/non-migrant health $[10,11]$.

Moving from a rural to an urban environment can expose migrants to changes in diet, social behaviors, and working and living conditions, which in turn produces changes in physical and mental health. Exposure to occupational hazards, diseases, and weaker community networks are among the observed negative effects of migration on rural-urban migrants' health, while increased economic opportunities, higher quality educational services, and more permissive social norms found within urban areas have been hypothesized to positively impact rural-urban migrant health [12-15]. The extent to which processes of adjustment narrow the gap between migrant and non-migrant health over time - referred to as the "adaptation effect"-is impacted by the strength of migrants' social networks, health literacy, and length of stay in the urban environment [11, 16]. With longer residence in urban areas, migrants may gain awareness of available health services, trust in health providers, and awareness of how best to utilize urban services [17, 18].

The context of reception, characterized by the degree to which social attitudes and governmental policies in urban environments are "migrant-friendly," can also impact migrant health service utilization and health outcomes [19]. Urban slums pose particular challenges for migrants. In Dhaka, where more than one-third of the urban population live in slums, overcrowding, housing insecurity, insufficient water and sanitation systems, and unregulated health service provision have contributed to poor health outcomes among residents, particularly with respect to maternal and child health [20-22]. Slum residents face eviction or threat of eviction, destruction of dwellings, high rates of crime and exploitation, and increased vulnerability to injury and disease [23, 24]. With limited access to employment, education, and social networking opportunities, slum residents may fall into poverty traps that intersect with and exacerbate health inequalities $[23,25]$.

Low-income urban residents in Bangladesh have limited opportunities for quality, public health care as a result of poor coordination between the Ministry of Health and Family Welfare and the Ministry of Local Government, Rural Development and Cooperativesthe two ministries responsible for overseeing health in urban areas [24]. In the absence of adequate public service provision, slum residents seek health care from an unregulated private sector, in which pharmacies and non-traditional doctors provide the majority of services [21]. Interventions that bring door-to-door health services to urban slum residents have had some success increasing women's access to maternal and child health services in Bangladesh [26]. However, these efforts fail to reach individuals who work long hours away from home, frequently change residences, or are homeless [27]. Urban slum populations are characterized by heterogeneity and high mobility due to residents' ongoing search for economic opportunities. These factors can interfere with slum residents' ability to receive followup health care and build the cohesive social networks needed to access effective care from trusted providers $[28,29]$. A reluctance of skilled staff to work in slum areas and a suspicion among community leaders of new interventions proposed in urban informal settlements create additional challenges for improving the health service environment for low-income slum residents [28].

\section{Utilization of Maternal and Child Health Services in Urban Slums}

The limited availability of affordable maternal and child health services for low-income women in urban Bangladesh, combined with limited knowledge of and misconceptions about available services, have contributed to poorer maternal and child health outcomes among slum residents compared to non-slum residents [26, 30]. Compared to non-slum residents, slum dwellers in Bangladesh have higher rates of maternal and neonatal mortality, higher rates of child malnutrition, and higher overall morbidity [22, 23, 31, 32].

Urban slum communities also have lower uptake of antenatal care (ANC), facility deliveries, skilled assisted deliveries, and child immunization compared to nonslum residents [33]. Women's health knowledge, which is strongly linked to education, influences women's utilization of antenatal care services, delivery attended by a trained professional, and complete immunization coverage for their children [34]. Among urban women living in Nairobi slums, education, wealth, being advised during ANC visits to deliver at a facility, pregnancy "wantedness," and parity were associated with delivery in an "appropriate" facility, which was defined as a hospital or clinic that offers basic essential obstetric care services and is owned and/or operated by the government, a large non-governmental organization, or 
religious and missionary groups [35]. Other factors associated with facility-based deliveries include maternal education, parity/birth order, rural/urban residence, household wealth/socioeconomic status (SES), distance to the nearest facility, and number of ANC visits [36]. Among slum residents in India, suboptimal vaccination coverage has been linked to SES, low levels of community participation, limited awareness about the importance of and vaccination schedules, and frequent migration [37].

Migration status can create additional barriers to maternal and child health service uptake, especially during the initial years after arrival. Lack of familiarity with urban maternal health services and lack of a "feltneed" for such services can lead to under-utilization of such services among migrant women [18]. Compared to urban-urban migrants, rural-urban migrants in subSaharan Africa were significantly less likely to utilize prenatal and delivery care services [38]. Compared to settled-migrants, recent migrants have lower rates of utilization of ANC services and lower rates of immunization coverage [39, 40]. The under-utilization of $\mathrm{MNCH}$ services among recently migrated women in South Asian cities has also been attributed to having multiple children, low levels of literacy, and marriage to an unskilled worker [17].

Under-utilization of services in urban slums can have a life-long impact on maternal and child health outcomes. Use of informal obstetric services, such as delivery attended by an unqualified birth attendant, is common among slum residents and can increase risk of death and disability during childbirth [41]. Delivering outside of a health facility or without the supervision of a trained professional is associated with higher levels of maternal morbidity and mortality [42]. Utilization of formal antenatal services exposes mothers to information on optimal breastfeeding and newborn care practices, which can drastically improve child health [43, 44]. More research is needed to understand the impact of migration on maternal and child health service utilization in urban slums.

\section{Objectives}

This study examines the relationship between migrant status and duration ( $<=9.99$ years, $10-19.99$ years, $20+$ years, native-born) and maternal and child health outcomes among rural-urban migrant women in Dhaka (North and South) and Gazipur City Corporations,
Bangladesh. By identifying factors associated with uptake of critical MNCH services, such as ANC visits and facility-based deliveries, our analysis aims to target specific coverage gaps among rural-urban migrant women. Identifying associations between migration status and health outcomes, including child's immunization coverage and women's use of modern contraceptives, can also lead to better understanding of migrant health-seeking behaviors.

\section{Materials and Methods}

This study analyzes data collected by the Urban Health and Demographic Surveillance System (UHDSS) in Bangladesh. The UHDSS was developed in 2015 to monitor the health services provided by the Urban Primary Health Care Project in select slums of Dhaka (North and South) and Gazipur City Corporations. Through partnerships with urban local bodies and NGOs, the Urban Primary Health Care Project has delivered primary health care services in city corporations and municipalities in urban Bangladesh since 1998. As a cross-sectional study, the data reflects variations in health service utilization and $\mathrm{MNCH}$ health outcomes by migrant duration. A limitation of this design is an inability to account for the effects of migrants' pre-departure health status and/or to determine whether associations with duration in the city are actually caused by additional time in the city or simply reflect variation across arrival cohorts [10].

This study analyzed data collected from slums in Dhaka City North (Korail and Mirpur), Dhaka City South (Dhalpur and Shayampur), and Gazipur City Corporations (Tongi). UHDSS selected large slums (with at least 100 households) in order to achieve economies of scale and improve follow-up [45]. While there are many small slums in Dhaka, these larger slums included in UHDSS are representative of more than $50 \%$ of the informal settlement population who live in large slums (Fig. 1) [45]. Our analytical sample aligns with UHDSS baseline population and socioeconomic census data, with the majority of respondents located in Tongi (37.9\%) and Korail (28.9\%) (Table 1) [46]. Our sample also reflects disparities in wealth and education found in the UHDSS population. The poorest and least educated residents were located in Korail, considered the largest slum in Bangladesh. Korail also had the highest percentage of residents who were new migrants 
$(<10$ years in the city). The slums do not vary considerably in age distribution or household size.

Fieldworkers who received training on data collection and interviewing techniques collected data on pregnancy outcomes, mortality, marriage and divorce, migration status, household headship, safe motherhood practices, and fertility regulation [45]. Data on safe motherhood practices (ANC visits, place of delivery, delivery attendant, mode of delivery), fertility regulation, HIV/AIDS/STD knowledge, women's experiences of and attitudes towards violence, and child health (child illness and immunization coverage) were collected from 1063 ever-married women between the ages of 15-49 who had a child younger than 24 months. We restricted our analysis to currently married mothers $(n=1053)$ and dropped those who reported a birth that may have occurred prior to migrating to Dhaka: a total of 112 women. This restriction allowed us to focus our analysis on mothers who had the greatest need for maternal and child health services. Compared to analyses of the full sample of currently married women, applying this sample restriction did not significantly alter our results. Our final analytical sample consisted of 941 mothers.

\section{Data Analysis}

We adopted two approaches to assess maternal, neonatal, and child health coverage. First, six binary variables indicating $\mathrm{MNCH}$ service utilization were examined to identify whether respondents had four or more ANC visits, whether they delivered in a facility (vs. at home/other), whether the delivery was performed by a qualified doctor, whether their child received all basic vaccinations, whether they used modern contraceptives, and whether they delivered via caesarean section. Each of these dichotomous indicators was examined separately within bivariate analyses of migrant $\mathrm{MNCH}$ service utilization (Figs. 2 and 4) and logistic regression analyses (Appendix Table 1). Next, we created an $\mathrm{MNCH}$ coverage index based on adequate ANC visits (four or more), facility delivery, doctor-assisted delivery, and child's receipt of all basic vaccinations. One point was allocated for each "yes" response to these conditions to create a total MNCH coverage index that ranged from 0 to 4. This index was used in bivariate analyses (Fig. 3) and ordinary least squares regression analyses (Table 3).

The independent variables were migration status, age, education, wealth, employment status, attitudes and experiences of violence, and slum. The migrant duration status variable is based on the household head and is classified as those who were born in Dhaka and those who migrated to Dhaka $<=9.99$ years ago, 10 19.99 years ago, and 20+ years ago. Wealth status was determined using principal components analysis for ownership of assets (such as bed, sewing machine, electric fan, radio, and mobile phone), with women grouped into quintiles. Education was grouped into four categories (none, 1-5 years, 6-9 years, and 10+ years). Employment was coded as a binary variable (housewives and other type of participation in the labor market). Violence was measured as an index with one point allocated for each yes response to whether the respondent had experienced any instances of violence at any time, whether she had experienced any instances of violence within the last year, and whether she believed violence against women was justified for any of the following reasons: she neglected of children, she had an argument with husband, she failed to provide food on time, she visited her family/friends without husband's permission, and she did not want to have sexual relations with her husband. Slums included Shayampur, Dhalpur, Mirpur, Korail, and Tongi.

We also tested these associations with a larger sample of 2673 pregnant women. For this sample, we examined women's MNCH outcomes using a 5-category duration variable (< 1 year, 1-9.99 years, 10-19.99 years, 20+ years, and born in Dhaka), age, education, wealth, occupation, and slum as independent variables. Women who were missing responses on ANC visits, facility delivery, or doctor-assisted delivery were analyzed as a separate subsample of women who may have delivered outside of Dhaka city. Results of ordinary least squares regression analyses using these variables appear in Appendix Tables 2 and 3.

Bivariate and multivariate regression analyses were conducted to examine the effects of our independent variables on key MNCH outcomes. To select the bestfitting model, we first identified models with the lowest AIC and BIC scores. Next, we examined the significance of the interaction terms $(p<0.05)$. Main effects models controlled for age (model 1), age, wealth, occupation, education, and violence (model 3), and age, wealth, occupation, education, violence, and slum (model 6). Interaction effects were also tested between migration and education, migration and wealth, and migration and slum. 


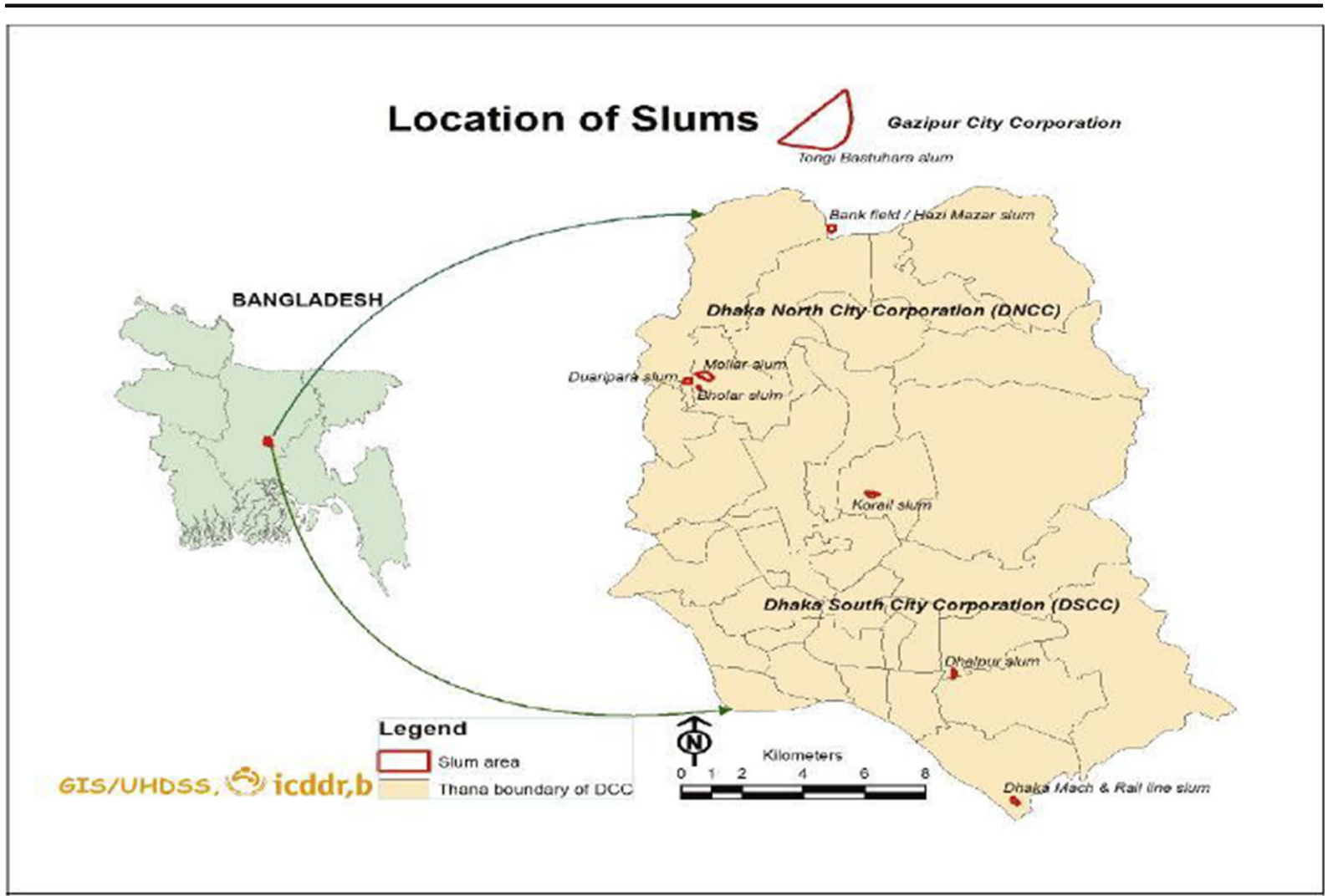

Fig. 1 Location of slums: Dhaka (North and South) and Gazipur City Corporations

\section{Results}

Bivariate Analyses

Table 1 shows variations in age, education, wealth, and migrant concentration across different informal settlements. The poorest slums, Korail and Shayampur, have the highest concentration of recent migrants, with $23 \%$ located in Korail and 27\% in Shayampur. Tongi has the highest concentration of Dhaka-born residents (31\%) with an average duration of 47.5 years. While slum residents were similar in age, residents of Korail had fewer years of education on average (3.74) compared to residents of Tongi (5.10) and lower average wealth scores compared to all other slums. Residents of Dhalpur had the highest average wealth of all slums.

Table 1 Variations in respondents' mean age, education, wealth, and distribution (\%) of recent migrants by slum. Distributions of the UHDSS population and analytical sample are shown for comparison

\begin{tabular}{lllllll}
\hline & UHDSS population & Analytical sample & Age & Education (years) & $\begin{array}{c}\text { Wealth } \\
\% \text { Recent migrants } \\
(<=9.99 \text { years })\end{array}$ \\
\hline Tongi & $41,786(35.3 \%)$ & $357(37.94 \%)$ & 24.90 & 5.10 & 3.45 & 11.76 \\
Korail & $36,422(30.8 \%)$ & $272(28.91 \%)$ & 24.99 & 3.74 & 2.26 & 23.16 \\
Mirpur & $23,049(19.5 \%)$ & $165(17.53 \%)$ & 24.71 & 4.39 & 3.07 & 3.80 \\
Dhalpur & $16,981(14.4 \%)^{*}$ & $81(8.61 \%)$ & 24.69 & 4.09 & 3.02 & 21.21 \\
Shayampur & & $66(7.01 \%)$ & 25.09 & 4.38 & 3.04 & 17.32 \\
Total & 118,238 & 941 & 24.89 & 4.45 & &
\end{tabular}

Source: UHDSS, 2016

*Combined population of Dhalpur and Shayampur 
In general, settlements with a higher concentration of recent migrants also tended to have the lowest levels of education and wealth. Ever after controlling for SES, observed disadvantages may reflect variations in the context of reception.

Table 2 presents bivariate analyses of respondents' socio-demographic characteristics by duration. The majority of respondents were between the ages of 20 and $29(62.8 \%)$, had $1-5$ years of education (44.7\%), and worked as housewives $(65.9 \%)$. A substantial wealth disparity was observed between Dhaka-born respondents and recent migrants, with $43.6 \%$ of recent migrants and only $4.6 \%$ of Dhaka-born respondents belonging to the poorest wealth quintile. By contrast, only $6.7 \%$ of recent migrants belonged to the wealthiest quintile compared to $22.2 \%$ of Dhaka-born respondents. Differences in schooling also favored those with longer experience in the city, though variations were much smaller. Migrants with $20+$ years in the city had comparable schooling to those born in Dhaka. Respondents who were born in the city were less likely to work, with $76.5 \%$ reporting being housewives compared to $59.5 \%$ among recent migrants. Most of the additional work activity among migrants involved day labor, which

Table 2 Distribution (\%) of respondents' socio-demographic background characteristics by duration status in select slums of Dhaka (North and South) and Gazipur City Corporation $(n=941)$

\begin{tabular}{|c|c|c|c|c|c|c|}
\hline \multicolumn{7}{|l|}{ Duration in Dhaka City } \\
\hline Socio-demographic characteristics & $<=9.99$ years & $10-19.99$ years & $20+$ years & Born in Dhaka & Total & Total \\
\hline & $\%$ & $\%$ & $\%$ & $\%$ & $n$ & $\%$ \\
\hline \multicolumn{7}{|l|}{ Age } \\
\hline $14-19$ & 21.5 & 12.7 & 17.8 & 14.4 & 155 & 16.5 \\
\hline $20-24$ & 39.9 & 37.5 & 27.3 & 37.3 & 319 & 33.9 \\
\hline $25-29$ & 23.9 & 30.5 & 28.1 & 33.3 & 272 & 28.9 \\
\hline $30-34$ & 6.1 & 13.5 & 15.9 & 9.8 & 118 & 12.5 \\
\hline $35-39$ & 4.9 & 5.4 & 8.2 & 4.6 & 59 & 6.3 \\
\hline $40+$ & 3.7 & 0.4 & 2.7 & 0.7 & 18 & 1.9 \\
\hline \multicolumn{7}{|l|}{ Education } \\
\hline No education & 21.5 & 24.3 & 24.0 & 22.2 & 220 & 23.4 \\
\hline $1-5$ years & 52.8 & 49.0 & 39.6 & 41.2 & 421 & 44.7 \\
\hline $6-9$ years & 20.9 & 22.0 & 27.6 & 28.8 & 236 & 25.1 \\
\hline $10+$ years & 4.9 & 4.6 & 8.7 & 7.8 & 64 & 6.8 \\
\hline \multicolumn{7}{|l|}{ Wealth } \\
\hline Poorest & 43.6 & 27.4 & 14.2 & 4.6 & 201 & 21.4 \\
\hline Poorer & 17.8 & 15.1 & 13.9 & 11.8 & 137 & 14.6 \\
\hline Middle & 22.7 & 24.3 & 17.2 & 19.6 & 193 & 20.5 \\
\hline Richer & 9.2 & 22.8 & 29.0 & 41.8 & 244 & 25.9 \\
\hline Richest & 6.7 & 10.4 & 25.7 & 22.2 & 166 & 17.6 \\
\hline \multicolumn{7}{|l|}{ Employment } \\
\hline Housewife & 59.5 & 66.4 & 63.9 & 76.5 & 620 & 65.9 \\
\hline Market labor & 40.5 & 33.6 & 36.1 & 23.5 & 321 & 34.1 \\
\hline \multicolumn{7}{|l|}{ Violence index } \\
\hline 0 & 25.2 & 25.9 & 26.0 & 22.9 & 238 & 25.3 \\
\hline 1 & 33.1 & 32.8 & 30.6 & 23.5 & 287 & 30.5 \\
\hline 2 & 21.5 & 19.7 & 25.7 & 39.2 & 240 & 25.5 \\
\hline 3 & 20.3 & 21.6 & 17.8 & 14.4 & 176 & 18.7 \\
\hline Total $(n)$ & 163 & 259 & 366 & 153 & 941 & $100 \%$ \\
\hline
\end{tabular}

Source: UHDSS, 2016 
Fig. 2 Distribution (\%) of respondents using key $\mathrm{MNCH}$ services by duration in slum. $\mathrm{MNCH}$ service indicators were analyzed as binary variables

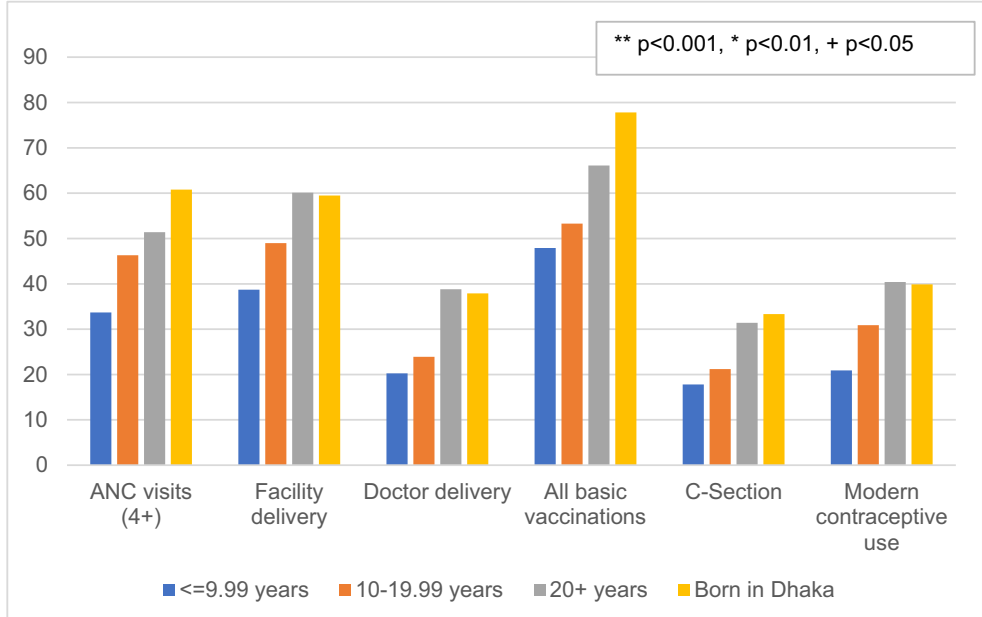

occupied $21 \%$ of recent migrants compared to just $9 \%$ of those born in the city.

Bivariate analyses of health outcomes show that the likelihood of receiving critical $\mathrm{MNCH}$ services increases with duration in Dhaka city (Fig. 2). Among recent migrants, approximately $34 \%$ had received four or more ANC visits, $20 \%$ had a doctor-assisted delivery, and nearly $40 \%$ had a facility delivery. In contrast, $61 \%$ of Dhaka-born respondents had four or more ANC visits, 38\% had a doctor-assisted delivery, and almost $60 \%$ delivered in a facility. The same trend emerges for child immunization, C-section delivery, and modern contraceptive use. Dhaka-born respondents and longterm migrants (20+ years in Dhaka) had higher rates of receipt of all basic vaccinations for their children $(77.8 \%$ and $66.1 \%$ compared to $47.9 \%$ for recent migrants) and use of C-section delivery (33.3\% and $31.4 \%$ compared to $17.8 \%$ of recent migrants). Only $20 \%$ of recent migrants used modern contraceptives compared to $40 \%$ of long-term migrants and $40 \%$ of Dhaka-born respondents.

Finally, Fig. 3 uses the index of total MNCH coverage $(0-4)$ to show the association of $\mathrm{MNCH}$ service uptake with duration in Dhaka city, years of education, higher wealth status, and slum block.

\section{Regression Analyses}

We tested multivariate models to assess whether the effects of duration in the city on $\mathrm{MNCH}$ coverage persist in the presence of controls for wealth, education, occupation, and slum status using ordinary least squares regression analysis. Table 3 begins with the overall index of four reproductive service indicators as the outcome variable, first without controls (model 1), then controlling for wealth, education, occupation, violence
Fig. 3 Mean MNCH coverage by duration in Dhaka city, education, wealth, and slum. The total $\mathrm{MNCH}$ coverage index $(0$ 4) was defined by adequate ANC visits (four or more), facilitybased delivery, doctor-assisted delivery, and child's receipt of all basic vaccinations

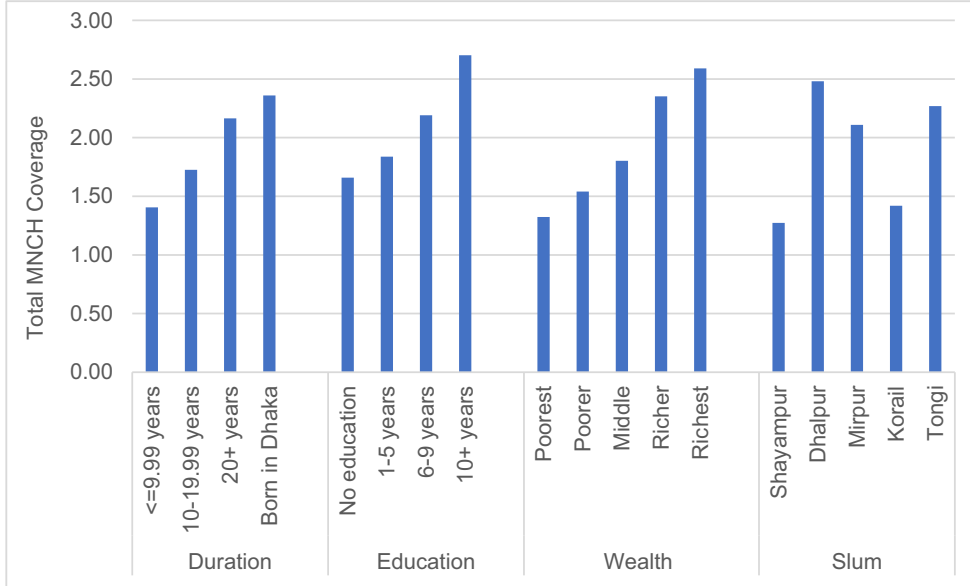


Table 3 Ordinary least squares regression estimates of duration and socio-demographic factors on total $\mathrm{MNCH}$ coverage

\begin{tabular}{|c|c|c|c|}
\hline & Model 1 & Model 2 & Model 3 \\
\hline \multicolumn{4}{|c|}{ Duration (Ref: born in Dhaka) } \\
\hline$<=9.99$ & $-0.930^{* *}$ & $-0.485^{* *}$ & $-0.389 *$ \\
\hline $10-19.99$ & $-0.636 * *$ & $-0.333 *$ & -0.235 \\
\hline $20+$ & -0.160 & -0.053 & -0.012 \\
\hline \multicolumn{4}{|l|}{ Age (Ref: 14-19) } \\
\hline $20-24$ & 0.216 & 0.151 & 0.192 \\
\hline $25-29$ & 0.076 & 0.040 & 0.070 \\
\hline $30-34$ & 0.078 & 0.027 & 0.098 \\
\hline $35-39$ & -0.028 & -0.029 & 0.006 \\
\hline $40+$ & $-0.650^{+}$ & -0.404 & -0.310 \\
\hline \multicolumn{4}{|c|}{ Education (Ref: none) } \\
\hline $1-5$ years & & 0.076 & 0.122 \\
\hline $6-9$ years & & 0.224 & $0.239^{+}$ \\
\hline $10+$ years & & $0.604 * *$ & $0.595 * *$ \\
\hline \multicolumn{4}{|c|}{ Wealth (Ref: poorest) } \\
\hline Second & & 0.082 & 0.073 \\
\hline Middle & & $0.342 *$ & $0.289^{+}$ \\
\hline Fourth & & $0.713 * *$ & $0.582 * *$ \\
\hline Highest & & $0.919 * *$ & $0.774 * *$ \\
\hline \multicolumn{4}{|c|}{ Employment (Ref: housewife) } \\
\hline Market labor & & $-0.360 * *$ & $-0.314^{* *}$ \\
\hline \multicolumn{4}{|l|}{ Violence index } \\
\hline 1 & & 0.122 & 0.077 \\
\hline 2 & & 0.137 & 0.095 \\
\hline 3 & & 0.057 & 0.024 \\
\hline \multicolumn{4}{|c|}{ Slum (Ref: Shayampur) } \\
\hline Dhalpur & & & $0.916 * *$ \\
\hline Mirpur & & & $0.769 * *$ \\
\hline Korail & & & $0.340^{+}$ \\
\hline Tongi & & & $0.731 * *$ \\
\hline Observations & 941 & 941 & 941 \\
\hline R-squared & 0.077 & 0.193 & 0.227 \\
\hline AIC & 3097.5 & 2992.4 & 2960.3 \\
\hline $\mathrm{BIC}$ & 3141.1 & 3089.3 & 3076.6 \\
\hline$-2 \log$ likelihood & -1540 & -1476 & -1456 \\
\hline df & 8 & 19 & 23 \\
\hline $\begin{array}{l}\text { Pseudo } \\
\text { R-squared }\end{array}$ & 0.0766 & 0.193 & 0.227 \\
\hline
\end{tabular}

Source: UHDSS, 2016

${ }^{* *} p<0.001, * p<0.01,{ }^{+} p<0.05$

(model 2), and then slum (model 3). Model 1 shows that recent migrants $(<=9.99$ years $)$ use nearly one fewer service than those born in Dhaka $(-0.930, p<0.001)$, with significant lower service use among those with 10 19.99 years $(-0.636, p<0.001)$. Model 2 includes controls for wealth, education, occupation, and exposure to violence. $\mathrm{MNCH}$ coverage increases with wealth and education: respondents belonging to the highest wealth quintiles and those with $10+$ years of education have the highest total $\mathrm{MNCH}$ coverage scores. Compared to housewives, respondents who participated in the labor market had significantly lower $\mathrm{MNCH}$ coverage scores. Experiences of violence were not significantly associated with $\mathrm{MNCH}$ coverage. After controlling for these factors, coefficients for urban duration are reduced by about $50 \%$. For instance, the coefficient for $<9.99$ years in the city is reduced to $-0.485(p<0.001)$. Model 3 adds further controls for slum. MNCH coverage was higher in all other slums compared to residents of Shayampur, with the highest MNCH coverage scores observed among residents of Dhalpur. These controls further attenuate the coefficient for $<9.99$ years in the city to $-0.389(p<0.01)$. Testing with ordered logistic regression and Poisson regression on both the full sample and restricted sample did not significantly alter the results. When adding controls for district of origin, the duration coefficients were not altered and none of the district categories were statistically significant.

Given significant effects of SES and slum on total MNCH coverage shown in Table 3, we selected model 3 to conduct further logistic regression analyses using each of our key MNCH indicators as separate outcome variables. All outcomes showed significantly lower utilization among recent migrants without SES controls. The full results of the model 3 estimates for all outcomes are shown in Appendix Table 1, and adjusted predicted probabilities of service utilization by urban duration are shown in Fig. 4. Compared to Dhaka-born respondents, recent migrants were $46 \%$ less likely to have four or more ANC visits $(p<0.05)$ and $62 \%$ less likely to have achieved full immunization coverage of all basic vaccinations for their child $(p<0.001)$. Although recent migrants were also less likely to have delivered in a facility than Dhaka-born residents, these results were not statistically significant. Compared to Dhaka-born residents, recent migrants were $52 \%$ less likely to use modern contraception $(p<0.05)$; however, differences in modern contraceptive use were not statistically significant for the other duration categories.

Wealth, education, occupation, and slum were significantly associated with most $\mathrm{MNCH}$ outcomes and 
Fig. 4 Adjusted predicted probabilities of respondents' MNCH service utilization by duration in slum. Significance levels $\left(* * p<0.001,{ }^{*} p<0.01,{ }^{+} p\right.$ $<0.05$ ) reflect regression results of service utilization relative to Dhaka-born respondents, as shown in Appendix Table 1

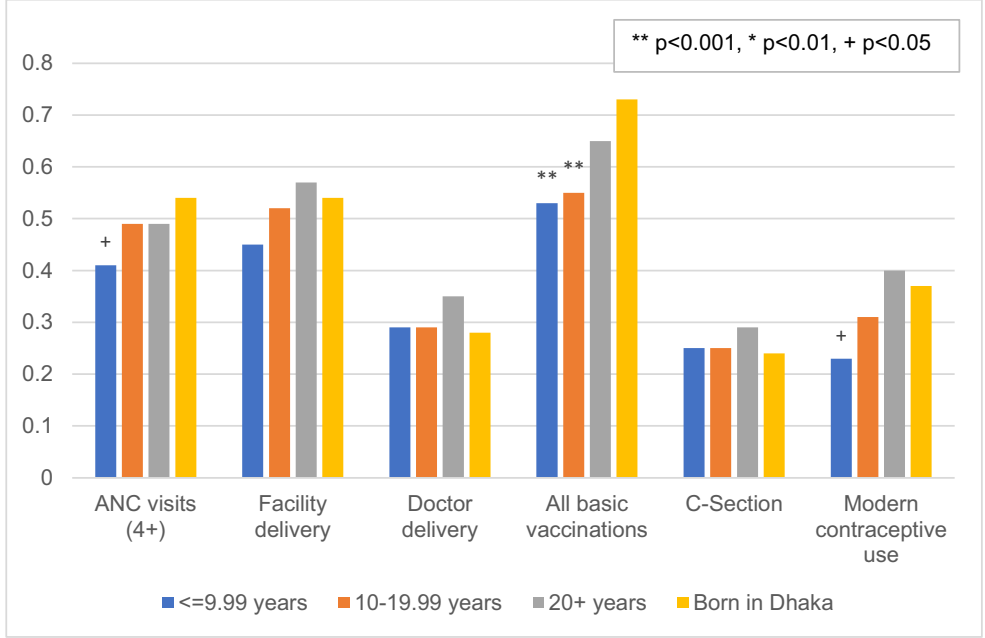

explained away a substantial share - yet not all —of the urban duration effect. Compared to respondents with no education, those with $10+$ years of education were 2.8 times as likely to receive four or more ANC visits $(p<$ $0.01)$, twice as likely to have a facility-based delivery ( $p$ $<0.05$ ), and 2.5 times as likely to have a trained doctor supervise their delivery when controlling for migration status $(p<0.01)$. Compared to respondents in the poorest quintile, those in the wealthiest quintile were twice as likely to have four or more ANC visits $(p<$ 0.01 ), three times as likely to have a facility delivery ( $p$ $<0.001)$, and five times as likely to have a doctor delivery $(p<0.001)$. Respondents in the fourth and highest wealth quintiles were 3.4 and 4.6 times as likely as respondents in the poorest quintile to have had a Csection $(p<0.001)$.

Interaction effects were tested between duration and education, duration and wealth, and duration and slum. These were tested for individual health outcomes and for the maternal care coverage index. We report results for the total MNCH coverage index in Appendix Table 2. None of these models improved the statistical goodness of fit of our models according to AIC or BIC tests. While certain interactions were statistically significant in isolation, the frequency of statistically significant interactions among the many effects tested was no greater than $5 \%$ (only 21 significant results out of 504 tests). For example, we observed that the odds of having four or more ANC visits for recent migrants were significantly higher in the highest wealth quintile. We observed a lower likelihood of contraceptive use among recent migrants in high-migrant slums (Mirpur, Korail, and Tongi) who had recently migrated and for residents of Mirpur regardless of migration status. In addition, migrants who had resided in Dhalpur or Korail for 10 19.99 years had lower odds of experiencing violence in the last year. No significant interaction effects were observed for total MNCH coverage, doctor delivery, facility delivery, immunization coverage, or delivery by C-section.

Analyses from our sample of 2178 pregnant women showed similar disparities based on migration status and SES. Recent migrants were less likely than Dhaka-born residents to have four or more ANC visits, while respondents with lower levels of wealth and education were less likely than their counterparts to have facility deliveries, doctor-assisted deliveries, and C-section deliveries. Recent migrants were more likely to be missing responses on delivery status compared to those born in Dhaka, suggesting that these women returned to their villages of origin to give birth. The results for models of MNCH coverage are shown in Appendix Table 3. Additional results are available upon request.

\section{Discussion}

Throughout much of the Global South, urban slums experience relatively lower levels of basic health coverage than more settled areas. These disparities reflect material disadvantage, ecological disadvantage, political disadvantage, and the role of slums as havens for recent rural-urban migrants, including many of the most disadvantaged migrant families. This study used data from a new Urban Health and Demographic Surveillance (UHDSS) in five slums in Dhaka (North and 
South) and Gazipur City Corporations to understand the disadvantages in $\mathrm{MNCH}$ service utilization among migrant women and their children. Compared to those born in the city, migrants were characterized by significant disadvantages in every $\mathrm{MNCH}$ indicator under study. We found no evidence of a healthy migrant effect. Instead, we observe that women from recent migrant households with less than 10 years in Dhaka, compared to a household head born in Dhaka, will use nearly one fewer service out of an aggregate index of four key $\mathrm{MNCH}$ services, with more modest disadvantages for those with 10 to 20 years of urban experience. We found no disadvantages for those with $20+$ years of migrant experience relative to the urban-born, and on some indicators, including facility delivery and doctor delivery, the level of service coverage among long-term migrants approximated that of urban-born. Our findings are in line with existing studies of healthcare access, which tend to find persistent migrant disadvantages in access to care, particularly among recent migrants. Most such findings come in the context of international migration, however, in which health care access may be explicitly limited to citizens. In this study of internal movement, migrant disadvantages must instead reflect a combination of material disadvantage, education, social networks, or spatial isolation.

To attempt to isolate the relationship between migration and urban health access, we accounted for multiple socioeconomic indicators and neighborhood variations in access, addressing their role as mediators and potential moderators of migrant disadvantage. We observed a strong positive association between wealth and $\mathrm{MNCH}$ coverage, with a more modest association with higher levels of schooling attainment. In fact, primary education (vs. none) did not significantly improve migrant $\mathrm{MNCH}$ coverage, a finding that deviates from previous studies of $\mathrm{MNCH}$ service utilization among low-income women in urban South Asia [17, 18]. To some extent, this may reflect the high level of school attendance and modest schooling disadvantages experienced by migrants. Women who were engaged in market employment were less likely to receive adequate coverage, suggesting a tradeoff between livelihood attainment and mother-and-child health. Controls for slum were also significant, with lower levels of utilization in areas with a high density of recent migrants, above and beyond the effects of migration itself. Slums with the lowest mean $\mathrm{MNCH}$ coverage-Shayampur and Korail—are also the two poorest slums. We conducted extensive tests of interactions to capture the ability of wealth, education or area of residence to moderate the migrant disadvantage and offering a potential fast track to healthcare access. We found no evidence to support such interactions, suggesting that the migrant disadvantage affects migrants of all backgrounds.

After controlling for these critical mediating factors, about $40 \%$ of the recent migrant disadvantages remained. The recent migrant disadvantage in the four-item index remained marginally significant. The most persistent migrant disadvantages were found in contraceptive utilization and immunization. This may reflect the ability of many recent migrants to gain access to at least some perinatal care like ANC and facility delivery by returning to their rural area of residence [47]. It may be more difficult to maintain access to services requiring long-term follow-up such as immunization and contraception. Future studies should explicitly address the extent to which rural-urban migrants utilized origin-area maternal health services, and in so doing account for potential deficits in quality of care for those rural services.

This study has some limitations. This cross-sectional survey captures variation by urban duration among different arrival cohorts rather than capturing the trajectories of assimilation among the same individuals over time. This is a common limitation of migrant health studies, but future work using UHDSS surveillance data can address these limitations by comparing births over time. Studies based on DHS-style surveys could also estimate fixed effects models comparing births occurring immediately before and after the onset of migration. This study also lacks detailed behavioral indicators that could help to explain the drivers of migrant health disadvantage relating to health-seeking knowledge, assimilation into the urban context, and access to health systems. In addition to directly collecting such behavioral measures, future studies can use GPS data on households and health care facilities to better isolate the role of proximity to care from behavioral mechanisms.

\section{Conclusion}

The disadvantages slum residents face compared to non-slum residents with respect to maternal and child health outcomes have been well documented 
$[26,28,33]$. New migrants arriving in Dhaka are further disadvantaged by limited familiarity with the urban service environment, inadequate service provision, and high mobility associated with housing and employment insecurity. The projected increase in Dhaka's urban population points to the urgent need for interventions capable of reaching Dhaka's highly mobile urban poor.

Using data from a new Urban Health and Demographic Surveillance (UHDSS) system, this study highlights the persistent and widespread burden of unequal access to $\mathrm{MNCH}$ care facing migrants to slum areas, even relative to the overall disadvantages experienced in informal settlements as a whole. These disparities can be addressed through a combination of increased healthcare supply to slum areas, user fee exemption, vouchers, and other price supports to reduce the cost of $\mathrm{MNCH}$ care, and specific behavioral supports aimed at migrant populations. In particular, electronic patient navigators and registries delivered over mobile phones have great potential to address the frequent service gaps and disruptions affecting migrants. The transition to the city, frequent movement between different slums, and work obligations all disrupt client connections to the continuum of care. Migrants already depend on mobile phones as a lifeline to deal with similar disruptions to social and economic relationships. Navigators, particularly with support from community health workers, would minimize the disruption associated with mobility and work, and provide a platform for referrals and delivery of a wide array of demand supports. We propose this package of interventions to address the intersecting effects of migration, poverty, and precarious living conditions on maternal and child health among migrants to Dhaka City. Such a comprehensive approach is needed to help Bangladesh achieve its Sustainable Development Goals (SDGs) of reducing urban inequity and providing safe and affordable universal health services.

Funding information The study was funded by the Government of the People's Republic of Bangladesh, Local Government Division, Ministry of Local Government, Rural Development and Cooperatives, Embassy of Sweden and Asian Development Bank. icddr,b gratefully acknowledges these donors for their support and commitment to the Centre's research effort. icddr,b is grateful to the Government of Bangladesh, Canada, Sweden, and the UK for providing core unrestricted support.

\section{References}

1. Afsar R. International migration and the development nexus: the case of Bangladesh. Regional Conference on Migration, Development and Pro-Poor Policy Choices in Asia, June 22-23 (2003). Dhaka, Bangladesh.

2. Al-Shoaibi AAA, Matsuyama A, Md K, et al. Perceptions and behavior related to noncommunicable diseases among slum dwellers in a rapidly urbanizing city, Dhaka, Bangladesh: a qualitative study. Nagoya J. Med. Sci. 2018;80(4):559-69. https://doi.org/10.18999 /nagjms.80.4.559.

3. Hossain S. Rapid urban growth and poverty in Dhaka city. Bangladesh e-J Sociol. 2008;5(1):57-80.

4. United Nations Development Programme [UNDP]. Bridging the urban divide in Bangladesh: towards a strategic approach to urban poverty reduction. Dhaka, Bangladesh; 2010.

5. Kuhn R. Internal migration: developing countries. Int Encyclopedia Soc Behav Sci. 2015:433-42. https://doi. org/10.1016/B978-0-08-097086-8.31120-5.

6. Kuhn R. Identities in motion: Social exchange networks and rural- urban migration in Bangladesh. Contrib Ind Sociol. 2003;37(1-2):311-37.

7. Haque MS. Migration trends and patterns in South Asia and management approaches and initiatives. Asia-Pac. Popul. J. 2005;20(3):39-57.

8. Palloni A, Morenoff JD. Interpreting the paradoxical in the Hispanic paradox: demographic and epidemiologic approaches. Ann. N. Y. Acad. Sci. 2006;954(1):140-74. https://doi.org/10.1111/j.1749-6632.2001.tb02751.x.

9. Lu Y. Test of the 'healthy migrant hypothesis': a longitudinal analysis of health selectivity of internal migration in Indonesia. Soc. Sci. Med. 2008;67(8):1331-9. https://doi. org/10.1016/j.socscimed.2008.06.017.

10. Nauman E, VanLandingham M, Anglewicz P. Migration, urbanization and health. In: White MJ, editor. International Handbook of Migration and Population Distribution, vol. 6; 2016. p. 451-64.

11. Ginsburg C, Bocquier P, Béguy D, Afolabi S, Augusto O, Derra $\mathrm{K}$, et al. Healthy or unhealthy migrants? Identifying internal migration effects on mortality in Africa using health and demographic surveillance systems of the INDEPTH network. Soc. Sci. Med. 2016;164:59-73. https://doi. org/10.1016/j.socscimed.2016.06.035.

12. Srinivasan S, Ilango P. Occupational health problems of women migrant workers in Thogamalai, Karur district, Tamil Nadu, India. SSRN J. 2013;2(2):21-6.

13. Li ML, Morrow M, Kermode M. Vulnerable but feeling safe: HIV risk among male rural-to-urban migrant workers in Chengdu, China. AIDS Care. 2007;19(10):1288-95. https://doi.org/10.1080/09540120701402855.

14. Nauman E, VanLandingham M, Anglewicz P, Patthavanit U, Punpuing S. Rural-to-urban migration and changes in health among young adults in Thailand. Demography. 2015;52(1): 233-57. https://doi.org/10.1007/s13524-014-0365-y.

15. Abas MA, Punpuing S, Jirapramukpitak T, Guest $P$, Tangchonlatip K, Leese M, et al. Rural-urban migration and depression in ageing family members left behind. $B r$. 
J. Psychiatry. 2009;195(1):54-60. https://doi.org/10.1192 /bjp.bp.108.056143.

16. Islam MM, Gagnon AJ. Use of reproductive health care services among urban migrant women in Bangladesh. BMC Womens Health. 2016;16(1):15. https://doi. org/10.1186/s12905-016-0296-4.

17. Kusuma YS, Kumari R, Kaushal S. Migration and access to maternal healthcare: determinants of adequate antenatal care and institutional delivery among socio-economically disadvantaged migrants in Delhi, India. Trop Med Int Health. 2013;18(10):1202-10. https://doi.org/10.1111/tmi.12166.

18. Gawde NC, Sivakami M, Babu BV. Utilization of maternal health services among internal migrants in Mumbai, India. $J$ Biosoc Sci. 2016;48(6):767-96. https://doi.org/10.1017 /S0021932016000195.

19. Schwartz SJ, Unger JB, Lorenzo-Blanco EI, Des Rosiers SE, Villamar JA, Soto DW, et al. Perceived context of reception among recent Hispanic immigrants: conceptualization, instrument development, and preliminary validation. Cultur Divers Ethnic Minor Psychol. 2014;20(1):1-15. https://doi. org/10.1037/a0033391.

20. Zulu EM, Beguy D, Ezeh AC, et al. Overview of migration, poverty and health dynamics in Nairobi City's slum settlements. J. Urban Health. 2011;88(S2):185-99. https://doi. org/10.1007/s11524-011-9595-0.

21. Adams AM, Islam R, Ahmed T. Who serves the urban poor? A geospatial and descriptive analysis of health services in slum settlements in Dhaka, Bangladesh. Health Policy Plan. 2015;30(Supp1 1):i32-45. https://doi.org/10.1093 /heapol/czu094.

22. Kamal N, Curtis S, Hasan MS, Jamil K. Trends in equity in use of maternal health services in urban and rural Bangladesh. Int. J. Equity Health. 2016;15(1):27. https://doi.org/10.1186/s12939-016-0311-2.

23. Ezeh A, Oyebode O, Satterthwaite D, Chen YF, Ndugwa R, Sartori J, et al. The history, geography, and sociology of slums and the health problems of people who live in slums. Lancet. 2017;389(10068):547-58. https://doi.org/10.1016 /S0140-6736(16)31650-6.

24. Shafique S, Bhattacharyya DS, Anwar I, Adams A. Right to health and social justice in Bangladesh: ethical dilemmas and obligations of state and non-state actors to ensure health for urban poor. BMC Med Ethics. 2018;19(S1):46-69. https://doi.org/10.1186/s12910-018-0285-2.

25. de Snyder VNS, Friel S, Fotso JC, Khadr Z, Meresman S, Monge $P$, et al. Social conditions and urban health inequities: realities, challenges and opportunities to transform the urban landscape through research and action. J. Urban Health. 2011;88(6):1183-93. https://doi.org/10.1007/s11524-0119609-y.

26. Jolly SP, Rahman M, Afsana K, Yunus FM, Chowdhury AMR. Evaluation of maternal health service indicators in urban slum of Bangladesh. PLOS ONE. 2016;11(10): e0162825. https://doi.org/10.1371/journal.pone.0162825.

27. McNab S, Freedman L. Maternal newborn health and the urban poor: a global scoping. July 2016. https://www. mailman.columbia.edu/sites/default/files/pdf/amdd-urbanmnh-report july-20-2016-final-report.pdf. Accessed May 24, 2019.

28. van de Vijver S, Oti S, Oduor C, Ezeh A, Lange J, Agyemang $\mathrm{C}$, et al. Challenges of health programmes in slums. Lancet. 2015;386(10008):2114-6. https://doi. org/10.1016/S0140-6736(15)00385-2.

29. van der Heijden J, Gray N, Stringer B, et al. 'Working to stay healthy', health-seeking behaviour in Bangladesh's urban slums: a qualitative study. BMC Public Health. 2019;19(1): 600. https://doi.org/10.1186/s12889-019-6750-0.

30. Ndugwa RP, Cleland J, Madise NJ, Fotso J-C, Zulu EM. Menstrual pattern, sexual behaviors, and contraceptive use among postpartum women in Nairobi urban slums. J. Urban Health. 2011;88(S2):341-55. https://doi.org/10.1007 /s11524-010-9452-6.

31. Govindaraj R, Raju D, Secci F, Chowdhury S, Frere J-J. Health and nutrition in urban Bangladesh: social determinants and health sector governance. Washington DC, USA; The World Bank; 2018.

32. Mannan MA. Burden of disease on the urban poor: a study of morbidity and utilisation of healthcare among slum dwellers in Dhaka City. Bangladesh Institute of Development Studies: Dhaka, Bangladesh; 2018.

33. Angeles G, Ahsan KZ, Streatfield PK, El Arifeen S, Jamil K. Reducing inequity in urban health: have the intra-urban differentials in reproductive health service utilization and child nutritional outcome narrowed in Bangladesh? J. Urban Health. 2019;96(2):193-207. https://doi. org/10.1007/s11524-018-0307-x.

34. Smith Greenaway E, Leon J, Baker DP. Understanding the association between maternal education and use of health services in Ghana: exploring the role of health knowledge. J. Biosoc. Sci. 2012;44(6):733-47. https://doi.org/10.1017 /S0021932012000041.

35. Fotso J-C, Ezeh A, Madise N, Ziraba A, Ogollah R. What does access to maternal care mean among the urban poor? Factors associated with use of appropriate maternal health services in the slum settlements of Nairobi, Kenya. Matern Child Health J. 2009;13(1):130-7. https://doi.org/10.1007 /s10995-008-0326-4.

36. Moyer CA, Mustafa A. Drivers and deterrents of facility delivery in sub-Saharan Africa: a systematic review. Reprod. Health. 2013;19(40) https://doi.org/10.1186/17424755-10-40.

37. Singh S, Sahu D, Agrawal A, Vashi MD. Ensuring childhood vaccination among slums dwellers under the National Immunization Program in India: challenges and opportunities. Prev. Med. 2018;112:54-60. https://doi.org/10.1016/j. ypmed.2018.04.002.

38. Cotton C. Migration and young women's access to maternal healthcare in sub-Saharan Africa. Health \& Place. 2019;55: 136-44. https://doi.org/10.1016/j.healthplace.2018.12.006.

39. Kusuma YS, Kaushal S, Garg R, Babu BV. Birth preparedness and determinants of birth place among migrants living in slums and slum-like pockets in Delhi, India. Sex Reprod Healthc. 2018;16:160-6. https://doi.org/10.1016/j. srhc.2018.04.004.

40. Crocker-Buque T, Mindra G, Duncan R, Mounier-Jack S. Immunization, urbanization and slums: a systematic review of factors and interventions. BMC Public Health. 2017;17(1):556. https://doi.org/10.1186/s12889-017-44737.

41. Essendi H, Mills S, Fotso J-C. Barriers to formal emergency obstetric care services' utilization. J. Urban Health. 
2011;88(2):356-69. https://doi.org/10.1007/s11524-0109481-1.

42. Anyait A, Mukanga D, Oundo GB, Nuwaha F. Predictors for health facility delivery in Busia district of Uganda: a cross sectional study. BMC Pregnancy Childbirth. 2012;12(1): 132. https://doi.org/10.1186/1471-2393-12-132.

43. Moran AC, Choudhury N, Uz Zaman Khan N, et al. Newborn care practices among slum dwellers in Dhaka, Bangladesh: a quantitative and qualitative exploratory study. BMC Pregnancy Childbirth. 2009;9(1):54. https://doi. org/10.1186/1471-2393-9-54.

44. Kimani-Murage EW, Norris SA, Mutua MK, et al. Potential effectiveness of Community Health Strategy to promote exclusive breastfeeding in urban poor settings in Nairobi, Kenya: a quasi-experimental study. J. Dev. Orig. Health Dis. 2016;7(2):172-84. https://doi.org/10.1017 /S2040174415007941.

45. Razzaque A, Chowdhury R, Mustafa AHMG. Making slums visible: slums and their dynamics in urban Bangladesh. In: Hossain, et al., editors. Slum health in
Bangladesh: insights from health and demographic surveillance. International Centre for Diarrhoeal Disease Research, Dhaka, Bangladesh; 2019. p. 7-25.

46. Razzaque A, Chowdhury R, Mustafa AHMG. The context of slums in Bangladesh. In: Hossain, et al., editors. Slum health in Bangladesh: insights from health and demographic surveillance. International Centre for Diarrhoeal Disease Research, Dhaka, Bangladesh; 2019. p. 26-53.

47. Clair K, Razzaque A, Islam MZ, Mia MN, Chowdhury R, Mustafa AHMG, et al. Identifying reproductive health coverage gaps for rural-vs. urban-born household heads in the slums in and around Dhaka City, Bangladesh. In Health and Socio-demographic Scenario: Slums of Dhaka $(N \& S)$ and Gazipur City Corporations. International Centre for Diarrhoeal Disease Research, Dhaka, Bangladesh; 2019.

Publisher's Note Springer Nature remains neutral with regard to jurisdictional claims in published maps and institutional affiliations. 